\title{
Magnetophoretic and Spectral Characterization of Oxyhemoglobin to Deoxyhemoglobin: Chemical vs Enzymatic Process
}

\author{
Mitchell Weigand ${ }^{1}$, Jenifer Gómez-Pastora ${ }^{1}$, James Kim ${ }^{1}$, Matthew Kurek ${ }^{1}$, Richard \\ Hickey $^{2}$, David Irwin ${ }^{3}$, Maciej Zborowski ${ }^{4}$, Andre Palmer ${ }^{5}$, and Jeffrey Chalmers ${ }^{1}$ \\ ${ }^{1}$ The Ohio State University \\ ${ }^{2}$ Ohio State University College of Engineering \\ ${ }^{3}$ University of Colorado - Anschutz Medical Campus \\ ${ }^{4}$ Cleveland Clinic \\ 5 the Ohio State University
}

October 15,2020

\begin{abstract}
A new method for hemoglobin $(\mathrm{Hb})$ deoxygenation and re-oxygenation, in suspension or within red blood cells, RBCs, is described using the commercial enzyme product, EC-Oxyraseß. This method using EC-Oxyrase has several advantages over established deoxygenation methodologies, such as avoiding side reactions that produce methemoglobin, eliminating the need of a sparging deoxygenation gas and airtight vessels, as well as easy re-oxygenation by washing and adding to a normal buffer with dissolved oxygen (DO). Spectra of deoxyHb and metHb from RBCs using three preparation methods: sodium dithionite, sodium nitrite and Oxyrase, show high purity of the deoxyHb using Oxyrase (with little to no methemoglobin or hemichrome production from side reactions). The deoxygenation action of Oxyrase follows first order reaction kinetics. Paramagnetic characteristics of intracellular hemoglobin in RBCs are compared using cell tracking velocimetry for healthy and sickle cell disease (SCD) donors and oxygen dissociation curves show that the function of healthy RBCs is unchanged after Oxyrase treatment. The results confirm that this enzymatic approach to deoxygenation produces pure deoxyhemoglobin, can be re-oxygenated easily, prepared aerobically and has similar paramagnetic mobility to the existing methods.
\end{abstract}

\section{Introduction}

The magnetic properties of hemoglobin $(\mathrm{Hb})$ and its derivative forms, have been documented since the 1930's (Pauling \& Coryell, 1936; Pauling \& Coryell, 1936), and since 2010, there have been at least 92 publications related to the magnetic separation of red blood cells (RBCs) based on their intracellular Hb content. Many groups are investigating label-free methods to remove RBCs from whole blood by exploiting the diamagnetic properties of white blood cells and the paramagnetic properties of RBCs when the Hb is in its deoxy or met form (Furlani 2007; Han \& Frazier, 2005; Han \& Frazier, 2006; Fattah, Ghosh \& Puri, 2016; Moore et al. , 2006; Norina, Shalygin \& Rastopov, 2000; Wu et al. , 2016; Kim, Massoudi, Antaki \& Gandini, 2012; Kashevsky, Zholud \& Kashevsky, 2015; Nam, Huang, Lim, Lim \& Shin, 2013; Kawano \& Watarai, 2012; Shen, Hwang, Hahn \& Park, 2012; Jung, Choi \& Han, 2010; Zborowski et al. , 2003; Moore et al. , 2018). The magnetic susceptibilities of oxygenated (oxyRBCs), deoxygenated (deoxyRBCs) and methemoglobinRBCs (metRBCs) were originally predicted (Pauling \& Coryell, 1936; Pauling \& Coryell, 1936; Zborowski et al. , 2003; Spees, Yablonskiy, Oswood \& Ackerman, 2001) from theoretical calculations and subsequently validated experimentally, with a slightly greater magnetic susceptibility for metRBCs when compared to deoxyRBCs. Although the magnetic properties of deoxyRBCs and metRBCs are well studied, the existing 
methods to deoxygenate RBCs in a reversible manner are complex. Thus, novel strategies to turn oxyRBCs into the magnetic deoxyRBCs are desired for blood taken from both healthy donors and patients suffering from hematological disorders.

In the studies to be presented below, human blood from normal and sickle cell disease, SCD, donors was used. SCD is a monogenic disorder where the patient is a heterozygous or homozygous carrier for the $\beta^{S}$ allele. This mutation causes a single nucleotide substitution from glutamic acid to valine in the $\beta$-globin chain and the resulting $\beta 6$ substitution results in hydrophobic interactions with adjacent HbS (sickle cell hemoglobin) chains. This polymerization is triggered at low $\mathrm{pO}_{2}$ and is also dependent on intracellular $\mathrm{HbS}$ and $\mathrm{HbF}$ (fetal hemoglobin) and $\mathrm{pH}$. Studying how SCD Hb is influenced by these parameters potentially makes possible new diagnostic and therapeutic techniques. One specific need is a rapid test to diagnose a SCD "crisis", in which rigid, sickled erythrocytes adhere to the endothelium and cause vaso-occlusion. A potential therapeutic example of the application of difference in magnetic properties of RBCs would be the return to the patient of normal RBCs during an exchange transfusion where plasma is returned to the patient with an apheresis device and all of the removed RBCs are discarded. It is this discarded apheresis RBC product that is used in this present study (Bunn, 1997; Rees, Williams \& Glad, 2010; Stuart \& Nagel, 2004).

The most commonly used chemical reaction to yield metRBCs, the magnetic form of RBCs, is the addition of sodium nitrite to oxyHb RBCs (Doyle, Pickering, DeWeert, Hoekstra \& Pater, 1981; Winterbourn, 1985; Norina, Shalygin \& Rastopov, 2000; Nam, Huang, Lim, Lim \& Shin, 2013; Zborowski et al., 2003) in a simple, single step and has a conversion near 100\% (Winterbourn, 1985). This metHb is stable after several washing steps and is preferred to mimic the paramagnetic properties of deoxyRBCs due to its ease of preparation. However, metHb is not a realistic candidate for subsequent RBC use, such as fractionation studies of high and low content of $\mathrm{Hb}$ within RBCs, since the metHb loses its ability to bind with, and release oxygen (methemoglobinemia). The globin structure destabilizes upon metHb conversion to hemichrome when reacted with $\mathrm{H}_{2} \mathrm{O}_{2}$ or diazine. MetHb can react with semiquinones to form oxyHb once again, but the formation of MetHb is stable over a long period of time and is irreversible for practical uses such as paramagnetic RBCs separation with subsequent use of the RBCs. Winterbourn (1990) and Di Iorio (1981) prepared MetHb using superoxide or potassium ferricyanide but these methods are much less popular compared to using sodium nitrite. Additionally, the reaction between deoxyHb and $\mathrm{NaNO}_{2}$ produces the vasodilator NO and nitrosylated hemoglobin (Cosby et al. , 2003).

Methods to prepare deoxygenated RBCs, however, are much more complex. Several reports exist of using either bubbled $\mathrm{N}_{2}$, Ar, or another oxygen-free inert gas through the blood or applying a gentle vacuum (Benesch, Benesch, Renthal \& Maeda, 1972; Zijlstra, Buursma \& Meeuwsen-van der Roest, 1991; Kawano \& Watarai, 2012; Zborowskiet al. , 2003), add sodium dithionite (Moore, Schygulla, Strohm \& Kolios, 2016; Han \& Frazier, 2005; Shen, Hwang, Hahn \& Park, 2012; Jung, Choi, Han \& Frazier, 2010), or both methods at once (Lambeth \& Palmer, 1973; Azarov et al. , 2005; Hofrichter, Ross \& Eaton, 1974; Eaton, Hanson, Stephens, Sutherland \& Dunn, 1978). Moore et al. (2018) used a hollow fiber deoxygenator, but methods, such as this involving gas exchange, must keep the system sealed from the atmosphere. In order to characterize the hemoglobin, absorbance spectra of anaerobic samples must be measured using stoppedflow spectrophotometers to keep the sample free of oxygen. This equipment is more complex compared to basic spectrophotometers. Stopped-flow spectrophotometric measurements can be made directly on RBCs in a diffusion-limited reaction (Coin \& Olson, 1979) or directly to hemoglobin obtained from cell lysis. The oxygenation kinetics of deoxyRBCs and free deoxyHb are discussed in Coin \& Olson (1979) and several other studies have described kinetic models and rate constants for other reactions involving derivatives of hemoglobin (Antonini \& Gibson, 1960; Azarov et al. , 2005; Doyle, Pickering, DeWeert, Hoekstra \& Pater, 1981). These studies use stopped-flow spectrophotometers and extinction coefficients to calculate the concentrations of other forms of hemoglobin.

Another method to obtain deoxyHb involves the use of sodium dithionite. In an aqueous solution, sodium dithionite reacts with oxygen and water to produce sodium bisulfite and hydrogen peroxide. If used in dilute 
hemoglobin concentrations, hydrogen peroxide, and subsequently free radicals, become more abundant. In the solid phase, sodium dithionite will react with ambient oxygen to produce sulfite and thiosulfate, making weight measurement inaccurate. The actual amount dissolved into a sample must be determined from titration with a standard ferricyanide solution and following reduction at 420nm (or measuring absorption at $314 \mathrm{~nm}$, which is less accurate). Buffers for sodium dithionite must also be above $\mathrm{pH} 7.6$ due to instability. Lastly, dithionite has been shown to alter the isosbestic point between oxyHb, deoxyHb and carboxyHb (Di Iorio, 1981; Mook, Buursma, Gerding, Kwant \& Zijlstra, 1979; Zijlstra, Buursma \& Meeuwsen-van der Roest, 1991). These points make sodium dithionite experimentally inaccurate and risky in clinical settings.

In contrast, and to the best of our knowledge, no reports exist on the use of the commercial enzyme product, EC-Oxyrase \&. (referred to as Oxyrase moving forward, not to be confused with the company name), to deoxygenate RBCs. In brief, Oxyrase name was given to an enzyme that allows radiation-damaged cells to divide, without the enzyme entering or damaging the cell. With addition of a proton donor, the enzyme consumes dissolved oxygen and converts it to water in media deoxygenating the media without airtight containers or flushing the solution with inert gases (Adler \& Spady, 1997). The rate of DO removal (activity of Oxyrase), is highly $\mathrm{pH}$ dependent, with a maximum activity at $\mathrm{pH} 8.4$ and $55^{\circ} \mathrm{C}$ ("EC Oxyrase", 2019). Other uses of Oxyrase include growing anaerobic cells, increasing cell growth in the log phase, increasing maximum titer and protecting certain biomolecules from reactions with oxygen.

The active components of Oxyrase have been shown to repair damaged cells, accelerate cell growth and consume dissolved oxygen. These enzymes, which also originate from the cytoplasmic membrane fraction ofE. Coli, have high reactivity with NADH and succinate (Adler, Carrasco, Crow \& Gill, 1981). These processes are due to active electron transport chain, ETC, complexes by which ATP is produced from $\mathrm{NADH}$ or succinate and $\mathrm{H}^{+}$ions from within the cell. Mechanisms in eukaryotic and prokaryotic are identical, however they take place in different domains. Eukaryotic ETC takes place across the inner membrane of the mitochondria, between the matrix and inner membrane space while still within the outer membrane of the cell. Prokaryotic ETC takes place across the membrane, between the cytoplasm and outside of the cell. Five complexes (CI, CII, CIII, CIV, CV) are involved. Briefly, CI and CII catalyze the feed molecule (NADH or succinate for CI and CII, respectively) into ubiquinone $\left(\mathrm{QH}_{2}\right)$ and transport the product to CIII. CIII and CIV are cytochromes, which contain active heme molecules ( 6 for CIII and 2 for CIV). CIII transports $2 \mathrm{H}^{+}$ to CIV via cytochrome c. Cytochrome $\mathrm{c}$ is a mobile electron carrier, while the transport chain from CI or CII to CIII occurs within a supercomplex of CI-CIII-CIV or CII-CIII-CIV. CIV reduces dissolved oxygen with the ions from cytochrome c to produce $\mathrm{H}_{2} \mathrm{O}$. (Fisher, Adler, Shull \& Cohen, 1969; Guo, Gu, Zong, Wu \& Yang, 2018; Zhao, Jiang \& Zhang, 2011)

This study evaluates the performance of Oxyrase to remove oxygen from intracellular and free hemoglobin; thus resulting in changes in the magnetic susceptibility of hemoglobin, and correspondingly when the hemoglobin is in RBC, the RBC magnetic susceptibility. The results from the use of an Eppendorf BioSpectrometer Basic, and the Winterbourn equation (Winterbourn, 1990) and Cell Tracking Velocimetry, (presented in detail in Zborowski et al. (2003), Moore et al. (2006), Moore et al. (2000) and Zhang et al. (2005)) were used to experimentally quantify the deoxygenation of suspended $\mathrm{Hb}$ and $\mathrm{Hb}$ retained within RBCs, respectively. The motivation for this current study is to develop a convenient, easily reversible, nontoxic, single step deoxygenation of red cells. Future studies seek to separate RBC samples based on iron content and re-transfuse.

\section{Materials and Methods}

Blood samples were drawn from two healthy male (M1, M2) and female (F1, F2) donors with informed consents according to a protocol approved by the Institutional Review Board (IRB) from The Ohio State University (protocol number 38334). These donors' blood was collected into EDTA-coated vacutainers. Samples were then diluted 1:100 in PBS, pH 7.4. After dilution, RBC concentration and size were measured in a Multisizer 4e Coulter Counter (Beckman Coulter). Unlysed, oxygenated RBCs or oxyHb were converted to the deoxygenated state by adding Oxyrase (Oxyrase Inc.) with $60 \mathrm{wt} . \%$ Sodium DL-lactate to maintain a $\mathrm{pH}$ suitable for a rapid deoxygenation rate. For comparison, deoxyRBCs or deoxyHb were obtained using 3.7 
$\mathrm{mM}$ sodium dithionite (without passing an inert gas) and $5 \mathrm{mM}$ sodium nitrite was used for oxidation to the metHb form. Oxyrase and lactate were mixed by pipette and left in an aerobic environment for 30 minutes, and dissolved oxygen was confirmed to be near zero using a ThermoFisher Orion 083005MD dissolved oxygen probe. Free Hb and RBCs were added to PBS containing either Oxyrase/lactate, sodium dithionite or sodium nitrite while exposed to the atmosphere. RBCs from SCD patients was provided by Dr. Irwin at University of Colorado Anschutz Medical Campus as apheresis waste from three patients undergoing scheduled blood transfusions. These SCD blood samples were considered waste products and deidentified. Both normal and SCD samples were prepared identically.

Free $\mathrm{Hb}$ for characterization and kinetics studies was prepared by lysing healthy RBCs in a $-86^{\circ} \mathrm{C}$ freezer and thawing in a bath of room temperature water. This method of lysis was chosen over hypotonic membrane rupture because an anaerobic environment could not be maintained using a typical lysis buffer containing dissolved oxygen. Cell lysate was centrifuged at 2,000 RCF for 5 minutes in an Eppendorf 5415c centrifuge. Spectrophotometry was performed by adding the supernatant to cuvettes containing the appropriate salt or enzyme in an Eppendorf BioSpectrometer Basic while reaction times were followed manually using a stopwatch.

Cell tracking velocimetry (CTV) was performed as previously described (Zborowski et al. , 2003; Moore et al. , 2006; Mooreet al. , 2000; Zhang et al. , 2005). During this experiment, CTV samples were measured at a position within the magnet with a $\mathrm{S}_{\mathrm{m}}$ value of $224.9 \mathrm{TA} / \mathrm{mm}^{2}(6.47 \mathrm{~mm}$ from the converging axis of the pole pieces). $\mathrm{Hb}$ on a cellular basis was calculated using the Winterbourne equation with spectroscopy and calculated from CTV data using the method presented by Chalmers et al . (2017).

For free $\mathrm{Hb}$ samples prepared with dithionite and Oxyrase, the percentage of oxyHb and deoxyHb was calculated using the method presented by Tsao, Sethna, Sloan \& Wyngarden (1955). A linear correlation of the percentage of oxygen saturation as a function of a ratio of the extinction coefficients $\varepsilon_{575} / \varepsilon_{505}$ was obtained by measuring oxygen-saturated $\mathrm{Hb}$ and a completely anaerobic sample $(<1 \% \mathrm{DO})$ of deoxyHb. Using equal hemoglobin concentrations, the extinction coefficients in the Beer-Lambert law can be replaced with the absorbance reported by a spectrophotometer. The $100 \%$ oxyHb sample was diluted with PBS exposed to air because if left in an anaerobic buffer, the deoxygenation would take place. The first measurement after adding oxyHb took place at 10 seconds because mixing shortly after hemoglobin addition caused scattering and made the result unreadable. Due to the first order rate of reaction, the $100 \%$ oxygenated point was extrapolated and a correction factor was applied to match the $100 \%$ oxygenation point and the final point, at $0 \%$ oxygenation. OxyHb samples and those treated with sodium nitrite (suspected of also containing metHb and hemichrome) were evaluated using the equation reported by Winterbourn (1990).

Oxygen dissociation curves were determined by using a Hemox Analyzer (TCS Scientific Corp) while controlling temperature at $37^{\circ} \mathrm{C}$. For samples using Oxyrase, a temperature-controlled sample without Oxyrase and lactate was bubbled to $100 \%$ oxygenation using air, flushed out and refilled with a sample containing Oxyrase that was placed in a separate $37^{\circ} \mathrm{C}$ temperature bath and the measurements proceeded without bubbling nitrogen. During these experiments the sample temperature slightly deviated from the setpoint.

\section{Results and Discussion}

\section{Reactions with Free Hemoglobin from Healthy Donors}

Publications studying deoxygenated $\mathrm{Hb}$ reacting with oxygen and several biomolecules including spinach ferredoxin, horse metmyoglobin, horse heart ferricytochrome with dithionite report reactions occurring on the order of milliseconds (Coin \& Lambeth, 1979). The timescale of reaction, not the rate constants, is confirmed using a basic spectrophotometer rather than a robust, airtight stopped-flow spectrophotometer. The spectra and relative oxygenation state over time for 13.4 $\pm 2.7 \mathrm{SD} \mu \mathrm{M}$ free hemoglobin for three different reactions are shown in Figures 1A and 1B , respectively. Figure 1A is presented as a normalized absorption intensity. The spectra for dithionite-treated $\mathrm{Hb}$ has a notable shoulder at $630 \mathrm{~nm}$, consistent with that of metHb. According to Di Iorio (1981), unstable dithionite produces $\mathrm{H}_{2} \mathrm{O}_{2}$, which can oxidize oxyHb into metHb (Winterbourn, 1900). The reaction with Oxyrase, however, shows no unwanted secondary peaks. As 
expected, the reaction inFigure 1B with dithionite is completed on the order of milliseconds. The reaction with sodium nitrite is on the order of 1 minute and the reaction with Oxyrase is completed on the order of 5-10 minutes. Overlaid spectra from deoxyHb treated with Oxyrase shows no significant change to the isosbestic point at 505nm reported in Tsao, Sethna, Sloan \& Wyngarden (1955) (data not shown).

The manufacturer of Oxyrase defines 1 unit of EC-Oxyrase@ as the "amount of Oxyrase that, under defined conditions, reduces dissolved oxygen at the rate of $1 \%$ per second" ("Assay of Oxyrase Activity", 2019). In this study, we do not report Oxyrase in units defined by the manufacturer but rather the volume fraction of Oxyrase in the sample. In a reaction to eliminate dissolved oxygen, Oxyrase acts as the enzyme for dissolved oxygen reduction to water in the presence of an appropriate hydrogen donor. In the present case, Oxyrase and lactate are mixed beforehand to prepare the anaerobic solution before oxyHb is added.

Figures 2A, 2B presents the percent oxygenation of $\mathrm{Hb}$ over time with varying lactate molarities and Oxyrase concentrations. Interestingly, deoxygenation proceeds more slowly at higher concentrations of sodium lactate. It is suggested that this observation is a result of $\mathrm{pH}$ of the buffer and consistent with measured DO after an hour (Figures 3A, 3B). At high lactate concentration and acidic pH, DO remains in the mixture and therefore incomplete conversion of oxyHb to deoxyHb is achieved. However, at low lactate concentrations, near the reported optimal $\mathrm{pH}$ for Oxyrase at 8.4, DO measurements are near zero (Adler \& Spady, 1997; "EC Oxyrase", 2019). It should be emphasized that $\mathrm{pH}$ has a much stronger influence on DO than transport-limited kinetics due to increased viscosity from lactate, which is discussed in the next section.

Reactions with RBCs and CTV

Figure 4A presents the magnetic velocity characteristics of paramagnetic RBCs from healthy donors. These graphs include the settling velocity, $u_{s}$, versus the magnetic velocity, $u_{m}$, scatter plot with appropriate histograms aligned along the side and top, respectively. The range in distribution presented here is consistent with what we have reported earlier in a study of 17 healthy donors (Kim et al. 2020). Ongoing studies are investigating the significance of these distributions in healthy, anemic and patients with sickle cell disease.

The histograms indicate that the distributions in both velocities nearly overlap for all three treatment methods across all four donors. However, due to increased viscosity of the lactate added to the Oxyrasedeoxygenated samples, the magnetic and settling velocities appear offset from the dithionite and nitrite samples, which can clearly be seen by following the smooth cumulative curves. This trend is more pronounced in the $\mathrm{y}$-axis (settling velocity) than in the x-axis (magnetic velocity) and can be attributed to side reactions producing diamagnetic hemichrome (around $540 \mathrm{~nm}$ ) due to over-oxidation in the case of nitrite. For example, the spectra of $\mathrm{Hb}$ in suspension,Figure1A , indicates high amounts of hemichrome contaminating metHb solution produced from exposure to nitrite. There are no other derivative forms of hemoglobin present in these samples.

Figure $4 \mathrm{~B}$ represents the same data for the three SCD donors. The scatter data for SCD RBCs are significantly wider than the $\mathrm{u}_{\mathrm{m}}-\mathrm{u}_{\mathrm{s}}$ scatter data for healthy RBCs. A large distribution in RBC size is indicative of hypoxia and iron deficiency (Ycas, Horrow \& Horne, 2015; Sultana, Haque, Sultana \& Ahmed, 2013), however this metric does not differentiate these healthy and SCD donors using CTV. Data in Figure 4 suggest similar distributions between $\mathrm{u}_{\mathrm{s}}$ (which can be converted to cell size, assuming a constant cell density) histograms for healthy and SCD donors but shows that CTV is able to recognize a much wider $u_{m}$ (analogous to $\mathrm{pgHb} /$ cell, potentially more clinically relevant) histogram for SCD donors compared to heathy ones. Scatter plot data for SCD donors also have a stronger fit along a line with positive correlation between $\mathrm{u}_{\mathrm{m}}$ and $\mathrm{u}_{\mathrm{s}}$, indicating that smaller/less dense cells have lower mobility, and therefore less hemoglobin than larger/denser cells.

Although the gender and heterozygous/homozygous status of the sickle cell patients are unknown, scatter plot data in Figure 4Bsuggest that the SCD RBCs have a similar size to healthy RBCs, and not the rigid, elongated, polymerized homozygous HbSS RBCs.

Converting $\mathrm{u}_{\mathrm{m}}$ data from Figure 4 to pgHb per cell (Chalmers et al ., 2017), Figure 5A, 5B calculate 
the amount of hemoglobin per cell for healthy and sickle cell donors, respectively. In this analysis, we are able to take into account the increased viscosity of Oxyrase and lactate in the reaction medium as well as $\mathrm{u}_{\mathrm{s}}$ variations due to size. For each donor, the viscosity of the Oxyrase/lactate solution is calculated to match the average $u_{\mathrm{s}}$ between the dithionite and nitrite samples was calculated while using $0.89 \mathrm{mPa}^{*} \mathrm{~s}$ for water at room temperature for dithionite and nitrite. The experimentally calculated viscosities for Oxyrase/lactate CTV samples for all donors are presented inTable $\mathbf{1}$ along with average and standard error of the donor's iron status (Morison, K. R., \& Mackay, F. M., 2001). Most calculated viscosities are within $10 \%$ of that of PBS and the added viscous transport limitation to the reaction is assumed to be negligible compared to $\mathrm{pH}$ dependence.

Figure 6 compares average intracellular masses of $\mathrm{Hb}$ between preparations methods for each healthy and sickle cell donor. Interestingly, the average iron content between healthy and SCD donors is quite similar. Sickle cell disease originating from a $\beta$-globin chain mutation polymerizes into $\mathrm{HbS}$ and the charts suggest that $\mathrm{HbS}$ cells retain their intracellular hemoglobin in this form. Lastly, it is suggested that CTV results for deoxygenated RBCs, induced by eliminating DO (as is the function of RBCs in vivo ) reflect the amount of iron that is available for oxygen binding and dissociation. If this is the case, magnetic mobility measured this way may reflect overall cell health and performance better than total iron (which may be influenced by chemical reactions) or total hemoglobin (intracellular and free $\mathrm{Hb}$ ).

The deoxygenation enzyme is active at high $\mathrm{pH}$ and subsequent experiments reveal improved methods to deoxygenate RBC buffer without significantly altering the viscosity. Most notably, laboratory prepared AS-3 ( $\mathrm{pH}$ 5.8) with $\mathrm{NaOH}$ (added until the desired $\mathrm{pH}$ is achieved) is able to completely remove DO in 15 minutes. This AS-3 buffered media is chosen due to its RBC preservation properties and the enzyme is able to consume $\mathrm{H}^{+}$from citric acid while $\mathrm{NaOH}$ maintains the desired basic $\mathrm{pH}$. Figure 7 shows CTV data from donor F1 (on a different date) with AS-3 as the buffer at five different $\mathrm{pH}$. Settling velocity cumulative curves reveal that buffers with high $\mathrm{pH}$ have greater settling velocities than AS-3 with low $\mathrm{pH}$. This result is due to $\mathrm{NaOH}$ diluting the AS-3 and decreasing viscosity while equilibrium DO remains at zero. Using the same analysis to correct for viscosity, the pgHb/cell between the five buffers closely match (average 26.7, SD 1.1).

Figures $8 \mathrm{~A}$ presents the oxygen dissociation curves of healthy donor hemoglobin deoxygenated with $\mathrm{N}_{2}$ and two samples deoxygenated with Oxyrase (all samples $2 \mathrm{mg} / \mathrm{mL} \mathrm{Hb}$ ). The Hemox-Analyzer was used per protocol to obtain a normal curve controlled at $37^{\circ} \mathrm{C}$. The other two curves were obtained by adding hemoglobin to a completely deoxygenated buffer (maintained at $37^{\circ} \mathrm{C}$ by a separate water bath) and quickly filling the measurement chamber while keeping the other settings consistent. The first point in these data is the point of maximum oxygenation, which was matched with the control sample. The three curves are nearly identical, suggesting that the ability of Oxyrase-deoxygenated RBCs to bind to oxygen is identical to unaltered RBCs. The samples with Oxyrase and lactate have a small leftward shift from the control, which is consistent with that of a sample at lower temperature due to unconventional instrument use, shown inFigure 8B.

\section{Conclusions}

This study reports a new method for hemoglobin deoxygenation and compares the reaction timescales and magnetic velocities between three RBC treatment methods on healthy and sickled blood. Addition of enzymes used in the ETC makes possible the reversible deoxygenation of RBCs at ambient conditions with high purity of deoxyHb. CTV results confirm that healthy RBCs have similar paramagnetic behavior compared to accepted RBC treatments. Additionally, this enzymatic treatment works well with SCD blood, collected as apheresis waste, which has a similar amount of intracellular $\mathrm{Hb}$ as healthy donors. Intracellular iron calculations from measurements of RBCs in medium of different viscosities further confirm the CTV system accuracy. Further, AS-3 storage solution can be buffered to the optimum pH for Oxyrase activity, without the increased viscosity when using lactate. Oxygen-dissociation curves show that RBC interactions with these enzymes do not significantly affect the oxygen binding properties, suggesting this may be a viable step in clinical blood processing in the future. In future works the authors wish to observe the effects of maintaining low DO over the course of a donated blood unit's storage life (6 weeks) and fractionate healthy and SCD 
blood.

\section{Acknowledgements}

This work was supported in part by the National Heart, Lung, and Blood Institute (1R01HL131720-01A1)

\section{References}

Adler, H., \& Spady, G. (1997). The use of microbial membranes to achieve anaerobiosis. Journal of Rapid Methods \& Automation in Microbiology, 5(1), 1-12.

Adler, H. I., Carrasco, A. L. I. C. I. A., Crow, W. E. L. D. O. N., \& Gill, J. S. (1981). Cytoplasmic membrane fraction that promotes septation in an Escherichia coli lon mutant. Journal of bacteriology, 147 (2), 326-332.

Antonini, E., \& Gibson, Q. H. (1960). Some observations on the kinetics of the reactions with gases of natural and reconstituted haemoglobins. Biochemical Journal, 76(3), 534.

"Assay of Oxyrase Activity." Oxyrase, 2019, www.oxyrase.com/upload/documents/assay_of_oxyrase_activity.pdf

Azarov, I., Huang, K. T., Basu, S., Gladwin, M. T., Hogg, N., \& Kim-Shapiro, D. B. (2005). Nitric oxide scavenging by red blood cells as a function of hematocrit and oxygenation. Journal of Biological Chemistry, 280(47), 39024-39032.

Benesch, R. E., Benesch, R., Renthal, R. D., \& Maeda, N. (1972). Affinity labeling of the polyphosphate binding site of hemoglobin. Biochemistry, 11(19), 3576-3582.

Bunn, H. Franklin. "Pathogenesis and treatment of sickle cell disease." New England Journal of Medicine 337.11 (1997): 762-769.

Chalmers, J. J., Jin, X., Palmer, A. F., Yazer, M. H., Moore, L., Amaya, P., .. \& Zborowski, M. (2017). Femtogram resolution of iron content on a per cell basis: ex vivo storage of human red blood cells leads to loss of hemoglobin. Analytical chemistry, 89(6), 3702-3709.

Cosby, K., Partovi, K. S., Crawford, J. H., Patel, R. P., Reiter, C. D., Martyr, S., . . \& Huang, K. T. (2003). Nitrite reduction to nitric oxide by deoxyhemoglobin vasodilates the human circulation. Nature medicine, 9(12), 1498.

Coin, J. T., \& Olson, J. S. (1979). The rate of oxygen uptake by human red blood cells. Journal of Biological Chemistry, 254(4), 1178-1190.

Doyle, M. P., Pickering, R. A., DeWeert, T. M., Hoekstra, J. W., \& Pater, D. (1981). Kinetics and mechanism of the oxidation of human deoxyhemoglobin by nitrites. Journal of Biological Chemistry, 256(23), 1239312398.।

Di Iorio, E. E. (1981). Preparation of derivatives of ferrous and ferric hemoglobin. In Methods in enzymology (Vol. 76, pp. 57-72). Academic Press.

Eaton, W. A., Hanson, L. K., Stephens, P. J., Sutherland, J. C., \& Dunn, J. B. R. (1978). Optical spectra of oxy-and deoxyhemoglobin. Journal of the American Chemical Society, 100(16), 4991-5003.

"EC-Oxyrase." Oxyrase, 2019, www.oxyrase.com/products/antioxidant-products/ec-oxyraser.

Fattah, A. R. A., Ghosh, S., \& Puri, I. K. (2016). High gradient magnetic field microstructures for magnetophoretic cell separation. Journal of Chromatography B, 1027, 194-199.

Fisher, W. D., Adler, H. I., Shull, F. W., \& Cohen, A. (1969). Properties of a cell fraction that repairs damage to the cell division mechanism of Escherichia coli. Journal of bacteriology , 97 (2), 500-505.

Furlani, E. P. (2007). A model for blood cell transport and separation in a magnetophoretic microsystem. In Technical Proceedings of the 2007 NSTI Nanotechnology Conference and Trade Show (Vol. 3, p. 45). 
Furlani, E. P. (2007). Magnetophoretic separation of blood cells at the microscale. Journal of Physics D: Applied Physics, 40(5), 1313.

Guo, R., Gu, J., Zong, S., Wu, M., \& Yang, M. (2018). Structure and mechanism of mitochondrial electron transport chain. Biomedical journal , 41 (1), 9-20.

Han, K. H., \& Frazier, A. B. (2005). A microfluidic system for continuous magnetophoretic separation of suspended cells using their native magnetic properties. Proc. Nanotech, 1, 187-190.

Han, K. H., \& Frazier, A. B. (2005). Diamagnetic capture mode magnetophoretic microseparator for blood cells. Journal of Microelectromechanical Systems, 14(6), 1422-1431.

Han, K. H., \& Frazier, A. B. (2006). Paramagnetic capture mode magnetophoretic microseparator for high efficiency blood cell separations. Lab on a Chip, 6(2), 265-273.

Hofrichter, J., Ross, P. D., \& Eaton, W. A. (1974). Kinetics and mechanism of deoxyhemoglobin S gelation: a new approach to understanding sickle cell disease. Proceedings of the National Academy of Sciences, 71(12), 4864-4868.

Jung, Y., Choi, Y., Han, K. H., \& Frazier, A. B. (2010). Six-stage cascade paramagnetic mode magnetophoretic separation system for human blood samples. Biomedical microdevices, 12(4), 637-645.

Kashevsky, B. E., Zholud, A. M., \& Kashevsky, S. B. (2015). Hydrodynamic instability in a magnetically driven suspension of paramagnetic red blood cells. Soft matter, 11(33), 6547-6551.

Kawano, M., \& Watarai, H. (2012). Two-dimensional flow magnetophoresis of microparticles. Analytical and bioanalytical chemistry, 403(9), 2645-2653.

Kim, J. Gomez-Pastora J., Gilbert, C. J., Weigand, M., Walters, N.A., Reategui, E., Palmer, A.F., Yazer, M., Zborowski, M., Chalmers, J.J. (2020). Quantification of the Mean and Distribution of Hemoglobin Content in Normal Human Blood Using Cell Tracking Velocimetry. Analytical Chemistry. 92:1956-1962.

Kim, J., Massoudi, M., Antaki, J. F., \& Gandini, A. (2012). Removal of malaria-infected red blood cells using magnetic cell separators: A computational study. Applied mathematics and computation, 218(12), 6841-6850.

Lambeth, D. O., \& Palmer, G. (1973). The kinetics and mechanism of reduction of electron transfer proteins and other compounds of biological interest by dithionite. Journal of Biological Chemistry, 248(17), 6095-6103.

Linus, B., \& Coryell, D. The Magnetic Properties and Structure of the Hemochromogens and Related Substances.

Mook, G. A., Buursma, A., Gerding, A. L. I. E., Kwant, G., \& Zijlstra, W. G. (1979). Spectrophotometric determination of oxygen saturation of blood independent of the presence of indocyanine green. Cardiovascular Research, 13(4), 233-237.

Moore, L. R., Fujioka, H., Williams, P. S., Chalmers, J. J., Grimberg, B., Zimmerman, P. A., \& Zborowski, M. (2006). Hemoglobin degradation in malaria-infected erythrocytes determined from live cell magnetophoresis. The FASEB journal, 20(6), 747-749.

Moore, L. R., Mizutani, D., Tanaka, T., Buck, A., Yazer, M., Zborowski, M., \& Chalmers, J. J. (2018). Continuous, intrinsic magnetic depletion of erythrocytes from whole blood with a quadrupole magnet and annular flow channel; pilot scale study. Biotechnology and bioengineering, 115(6), 1521-1530.

Moore, L. R., Zborowski, M., Nakamura, M., McCloskey, K., Gura, S., Zuberi, M., ... \& Chalmers, J. J. (2000). The use of magnetite-doped polymeric microspheres in calibrating cell tracking velocimetry. Journal of Biochemical and Biophysical Methods, 44(1-2), 115-130. 
Moore, M. J., Schygulla, P. M., Strohm, E. M., \& Kolios, M. C. (2016, September). Single red blood cell oxygenation saturation imaging with multispectral photoacoustic microscopy. In 2016 IEEE International Ultrasonics Symposium (IUS) (pp. 1-4). IEEE.

c Viscosity of lactose and whey protein solutions. International Journal of Food Properties, 4(3), 441-454.

Nam, J., Huang, H., Lim, H., Lim, C., \& Shin, S. (2013). Magnetic separation of malaria-infected red blood cells in various developmental stages. Analytical chemistry, 85(15), 7316-7323.

Norina, S. B., Shalygin, A. N., \& Rastopov, S. F. (2000, May). Optical study of magnetic sedimentation and orientable properties of blood cells. In Optical Diagnostics of Biological Fluids V (Vol. 3923, pp. 155-162). International Society for Optics and Photonics.

Pauling, L., \& Coryell, C. D. (1936). The magnetic properties and structure of hemoglobin, oxyhemoglobin and carbonmonoxyhemoglobin. Proceedings of the National Academy of Sciences, 22(4), 210-216.

Rees, D. C., Williams, T. N., \& Gladwin, M. T. (2010). Sickle-cell disease. The Lancet , 376 (9757), 20182031.

Shen, F., Hwang, H., Hahn, Y. K., \& Park, J. K. (2012). Label-free cell separation using a tunable magnetophoretic repulsion force. Analytical chemistry, 84(7), 3075-3081.

Spees, W. M., Yablonskiy, D. A., Oswood, M. C., \& Ackerman, J. J. (2001). Water proton MR properties of human blood at 1.5 Tesla: Magnetic susceptibility, T1, T2, T, and non-Lorentzian signal behavior. Magnetic Resonance in Medicine: An Official Journal of the International Society for Magnetic Resonance in Medicine, 45(4), 533-542.

Stuart, M. J., \& Nagel, R. L. (2004). Sickle-cell disease. The Lancet, 364 (9442), 1343-1360.

Sultana, G. S., Haque, S. A., Sultana, T., \& Ahmed, A. N. (2013). Value of red cell distribution width (RDW) and RBC indices in the detection of iron deficiency anemia. Mymensingh medical journal: MMJ , 22 (2), 370-376.

Tsao, M. U., Sethna, S. S., Sloan, C. H., \& Wyngarden, L. J. (1955). Spectrophotometric determination of the oxygen saturation of whole blood. J. biol. Chem, 217(1), 479-488.

Winterbourn, C. C. (1985). Free-radical production and oxidative reactions of hemoglobin. Environmental health perspectives, 64, 321-330.

Winterbourn, C. C. (1990). Oxidative reactions of hemoglobin. In Methods in enzymology (Vol. 186, pp. 265-272). Academic Press.

Wu, W. T., Martin, A. B., Gandini, A., Aubry, N., Massoudi, M., \& Antaki, J. F. (2016). Design of microfluidic channels for magnetic separation of malaria-infected red blood cells. Microfluidics and nanofluidics, $20(2), 41$.

Yčas, J. W., Horrow, J. C., \& Horne, B. D. (2015). Persistent increase in red cell size distribution width after acute diseases: a biomarker of hypoxemia?. Clinica Chimica Acta , 448 , 107-117.

Zborowski, M., Ostera, G. R., Moore, L. R., Milliron, S., Chalmers, J. J., \& Schechter, A. N. (2003). Red blood cell magnetophoresis. Biophysical journal, 84(4), 2638-2645.

Zhang, H., Moore, L. R., Zborowski, M., Williams, P. S., Margel, S., \& Chalmers, J. J. (2005). Establishment and implications of a characterization method for magnetic nanoparticle using cell tracking velocimetry and magnetic susceptibility modified solutions. Analyst, 130(4), 514-527.

Zhao, R. Z., Jiang, S., Zhang, L., \& Yu, Z. B. (2019). Mitochondrial electron transport chain, ROS generation and uncoupling. International journal of molecular medicine , 44 (1), 3-15. 
Zijlstra, W. G., Buursma, A., \& Meeuwsen-Van der Roest, W. P. (1991). Absorption spectra of human fetal and adult oxyhemoglobin, de-oxyhemoglobin, carboxyhemoglobin, and methemoglobin. Clinical chemistry, 37(9), 1633-1638.

\section{Tables}

Table 1

\begin{tabular}{|c|c|c|c|c|c|c|c|c|c|}
\hline \multirow{2}{*}{ Donor } & \multirow{2}{*}{ Gender } & \multirow{2}{*}{ Status } & \multicolumn{3}{|c|}{ Avg pgHb/cell } & \multicolumn{3}{|c|}{ pgHb/cell SE } & \multirow{2}{*}{$\begin{array}{c}\text { Calculated } \\
\text { Viscosity }\left(\mathrm{Pa}^{2} \mathrm{~s}\right)\end{array}$} \\
\hline & & & Dithionite & Nitrite & Oxyrase & Dithionite & Nitrite & Oxyrase & \\
\hline M1 & Male & Healthy & 19.7 & 15.1 & 18.1 & 0.41 & 0.40 & 0.38 & $9.81 \mathrm{E}-04$ \\
\hline M2 & Male & Healthy & 17.1 & 17.5 & 18.4 & 0.53 & 0.49 & 0.31 & $1.03 \mathrm{E}-03$ \\
\hline F1 & Female & Healthy & 21.8 & 19.1 & 21.3 & 0.39 & 0.37 & 0.27 & $9.62 \mathrm{E}-04$ \\
\hline F2 & Female & Healthy & 14.3 & 13.5 & 19.2 & 0.54 & 0.39 & 0.29 & $1.02 \mathrm{E}-03$ \\
\hline SCD4 & Unknown & Sickle Cell & 19.8 & 21.5 & 16.0 & 0.27 & 0.44 & 0.22 & 7.44E-04 \\
\hline SCD5 & Unknown & Sickle Cell & 21.4 & 19.8 & 25.2 & 0.18 & 0.21 & 0.24 & $9.48 \mathrm{E}-04$ \\
\hline \multirow[t]{3}{*}{ SCD6 } & Unknown & Sickle Cell & 22.1 & 16.8 & 22.4 & 0.18 & 0.18 & 0.29 & $9.22 \mathrm{E}-04$ \\
\hline & & & & & & \multicolumn{3}{|c|}{ Measured Viscosity $\left(\mathrm{Pa}^{*} \mathrm{~s}\right)$} & $1.78 \mathrm{E}-03$ \\
\hline & & & & & & \multicolumn{3}{|c|}{ Literature Viscosity $(\mathrm{Pa} * \mathrm{~s})$} & $1.12 \mathrm{E}-03$ \\
\hline
\end{tabular}

\section{Figures}

Figure 1. (A) Spectra of oxyhemoglobin, deoxyhemoglobin and methemoglobin prepared using different methods. (B) Percent oxygenation over time is compared between the three hemoglobin reactions.

A

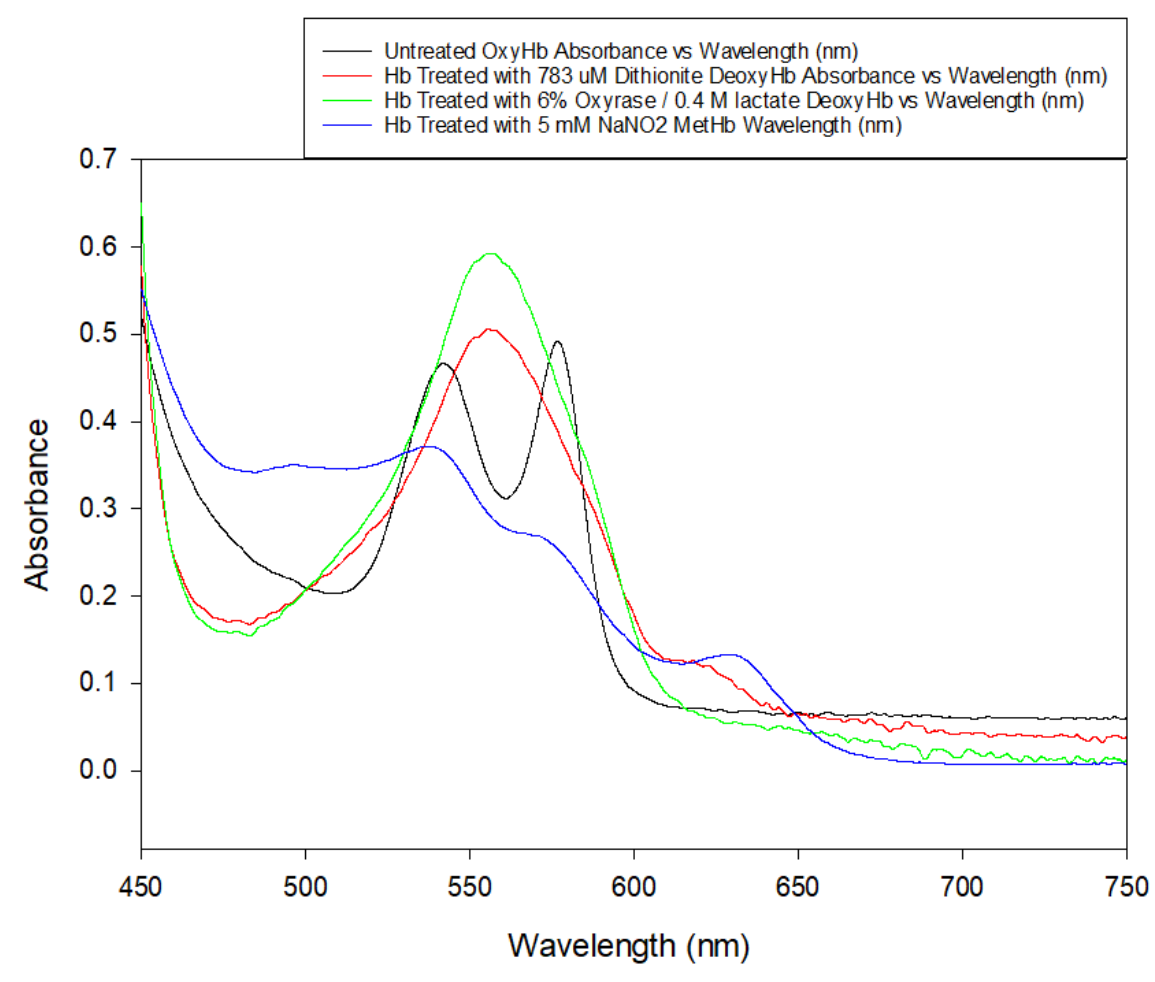

B 


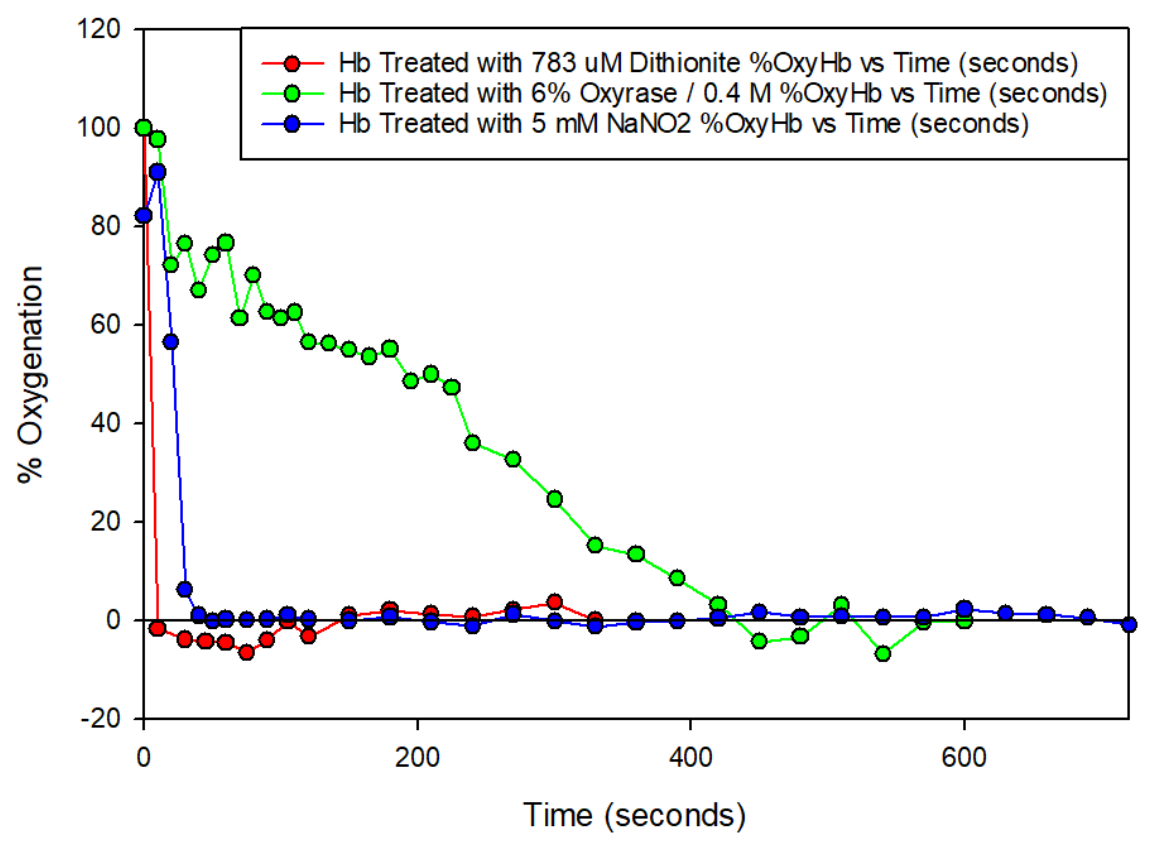

Figure 2. Percent oxygenation over time using Oxyrase with different lactate concentrations for (A) 4 vol\% Oxyrase and (B) 6 vol\% Oxyrase.

A

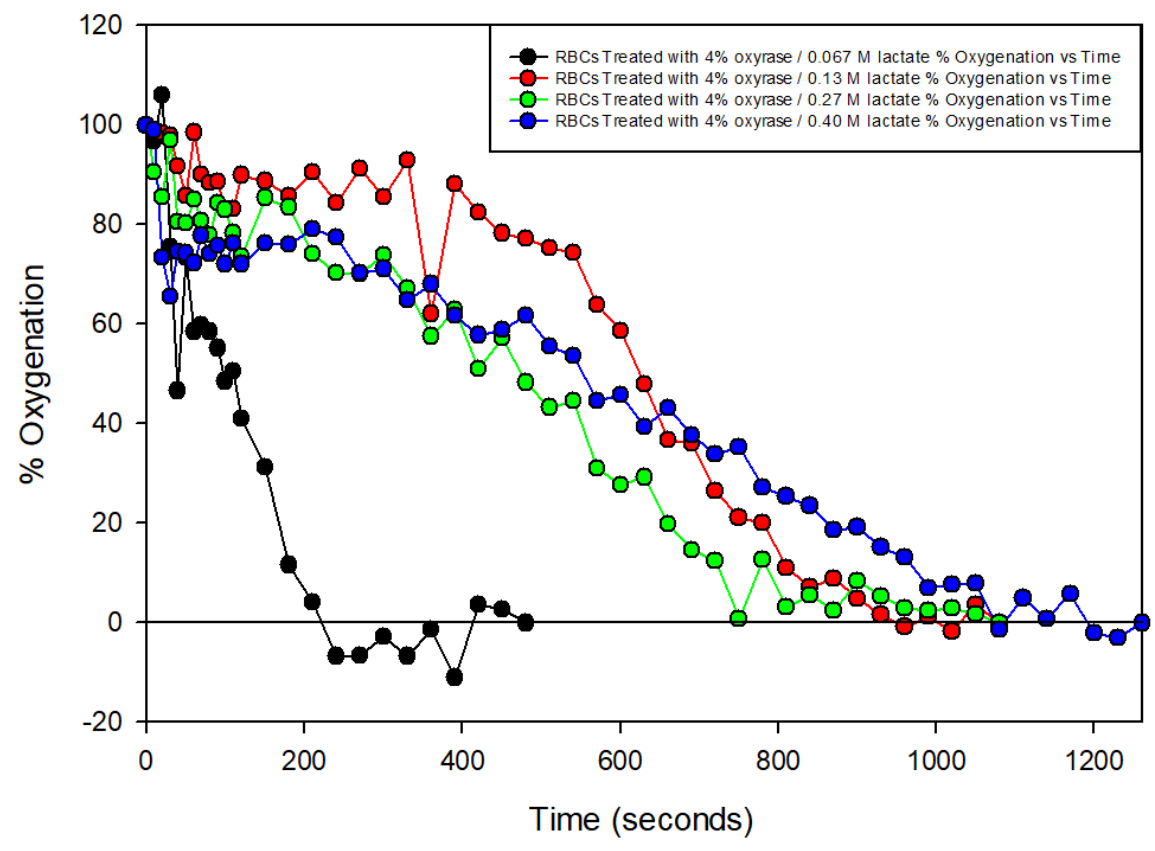

B 


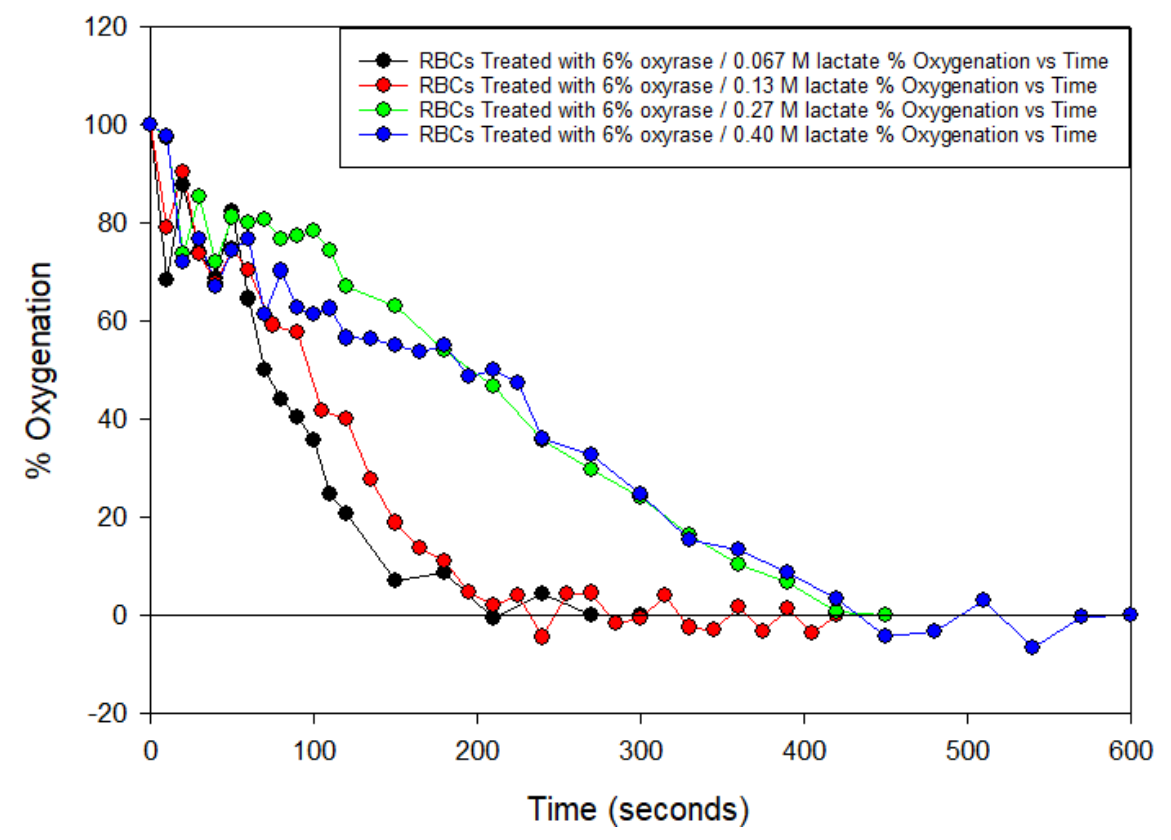

Figure 3. 3-dimensional map of (A) dissolved oxygen and (B) $\mathrm{pH}$, mapped over lactate molarity and vol\% Oxyrase.

A
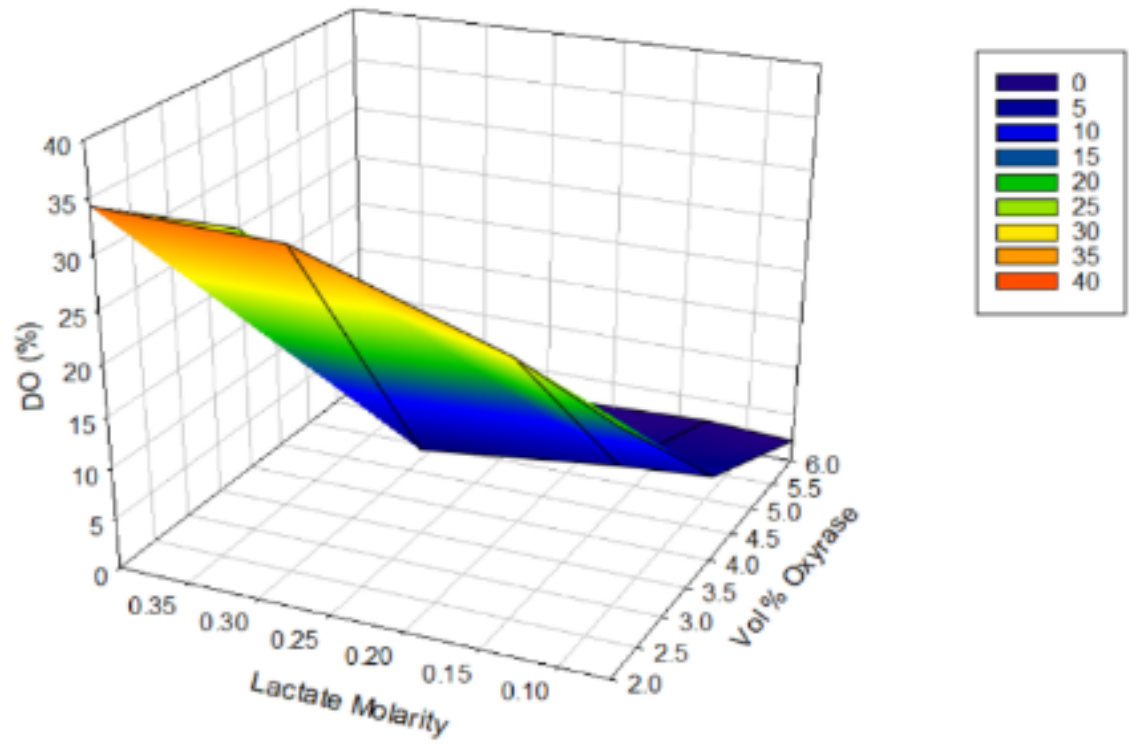

B 

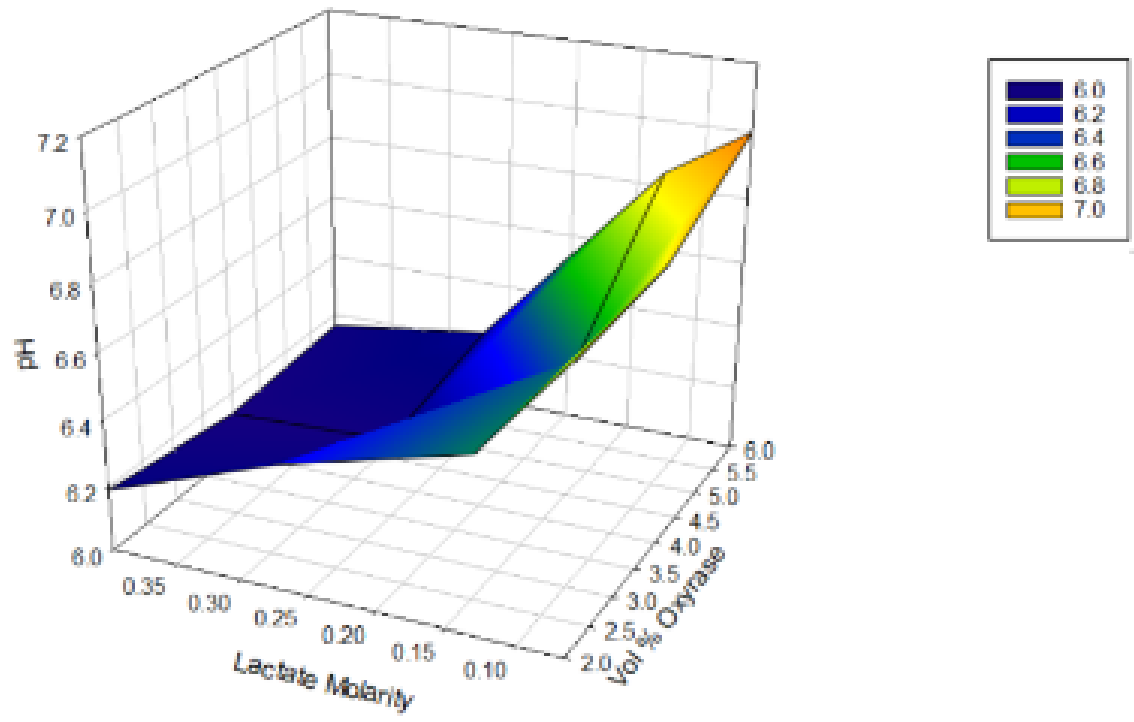

Figure 4. Scatter plots comparing paramagnetic RBCs prepared from three methods are overlaid for each donor. Magnetic and settling velocity histograms are superimposed above and to the side of the scatter plot with cumulative curves. Two healthy male and two healthy female donors (A, left) and three SCD donors of unknown gender (B, right) are shown.

A

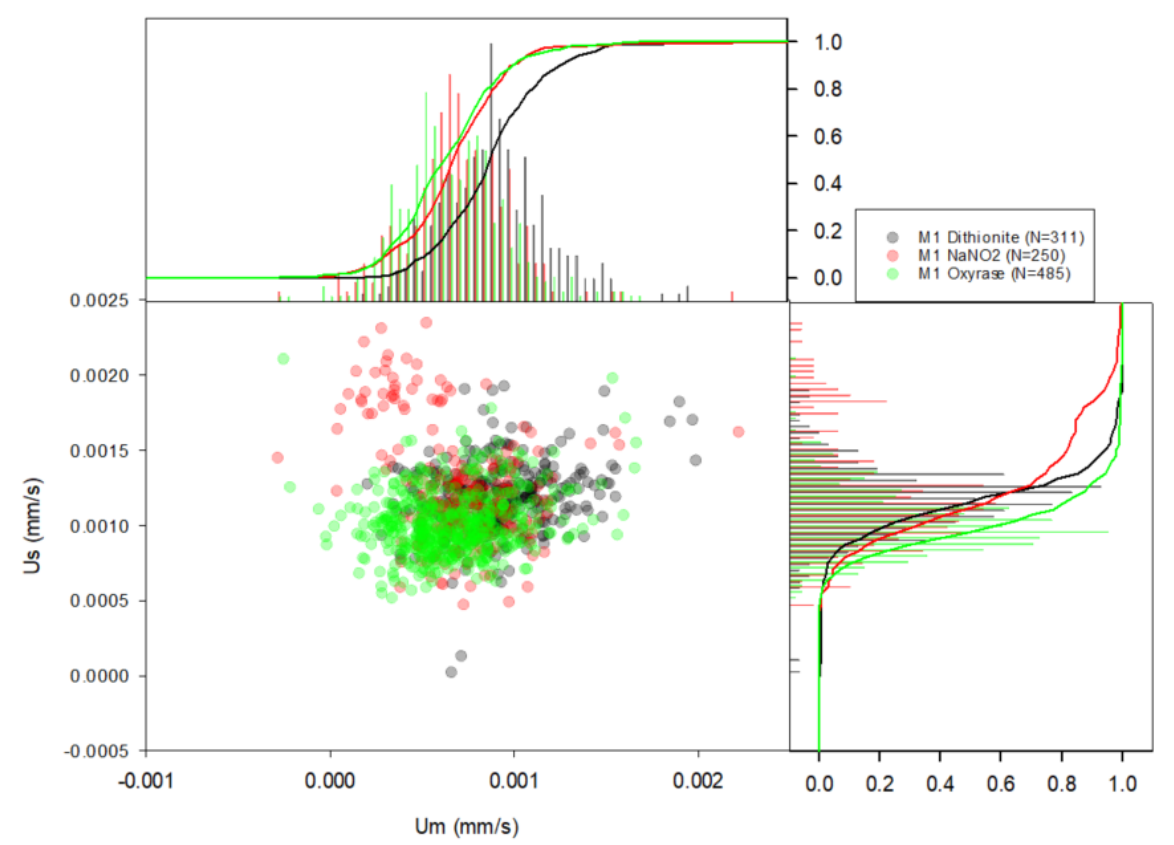



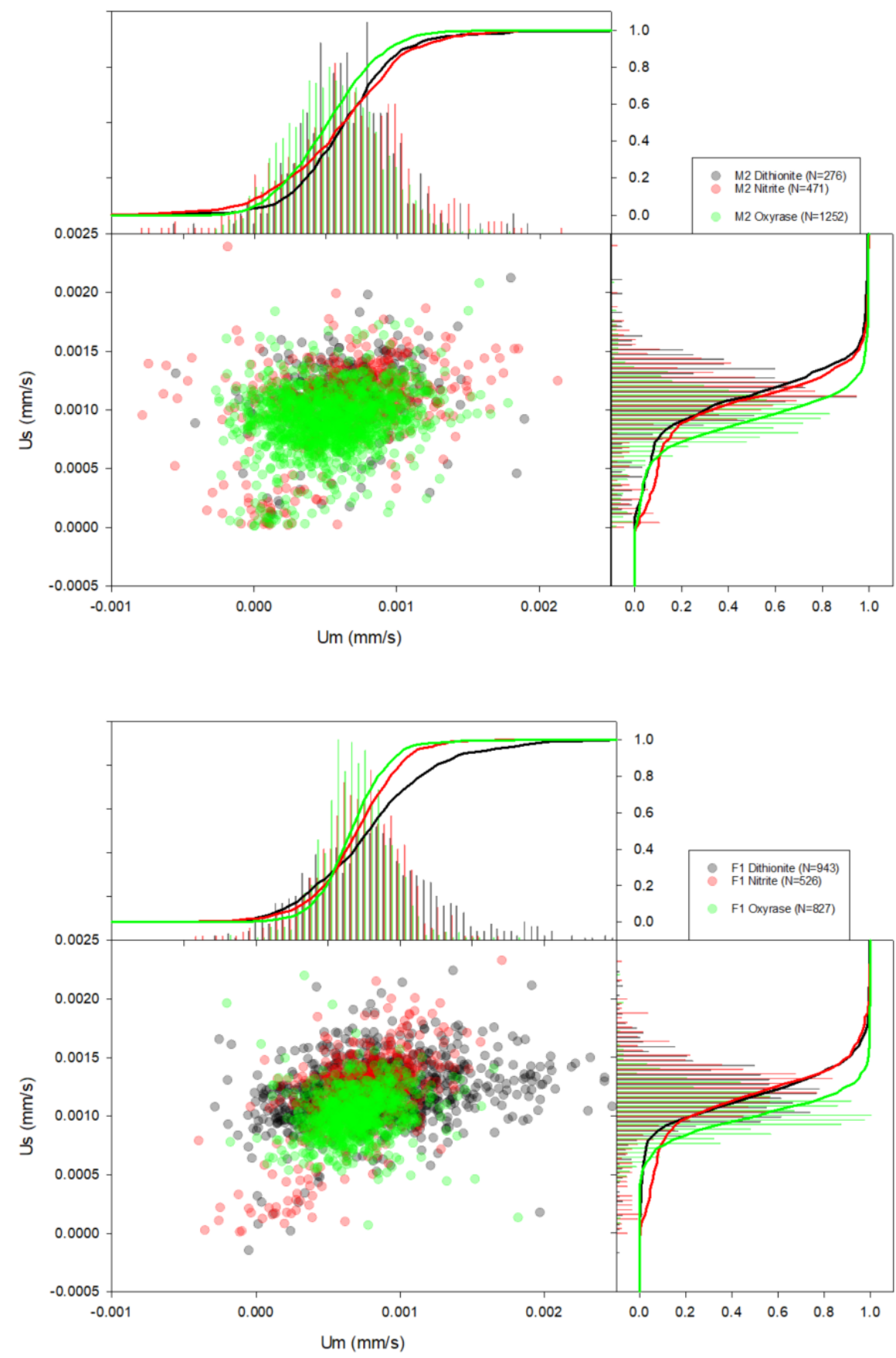


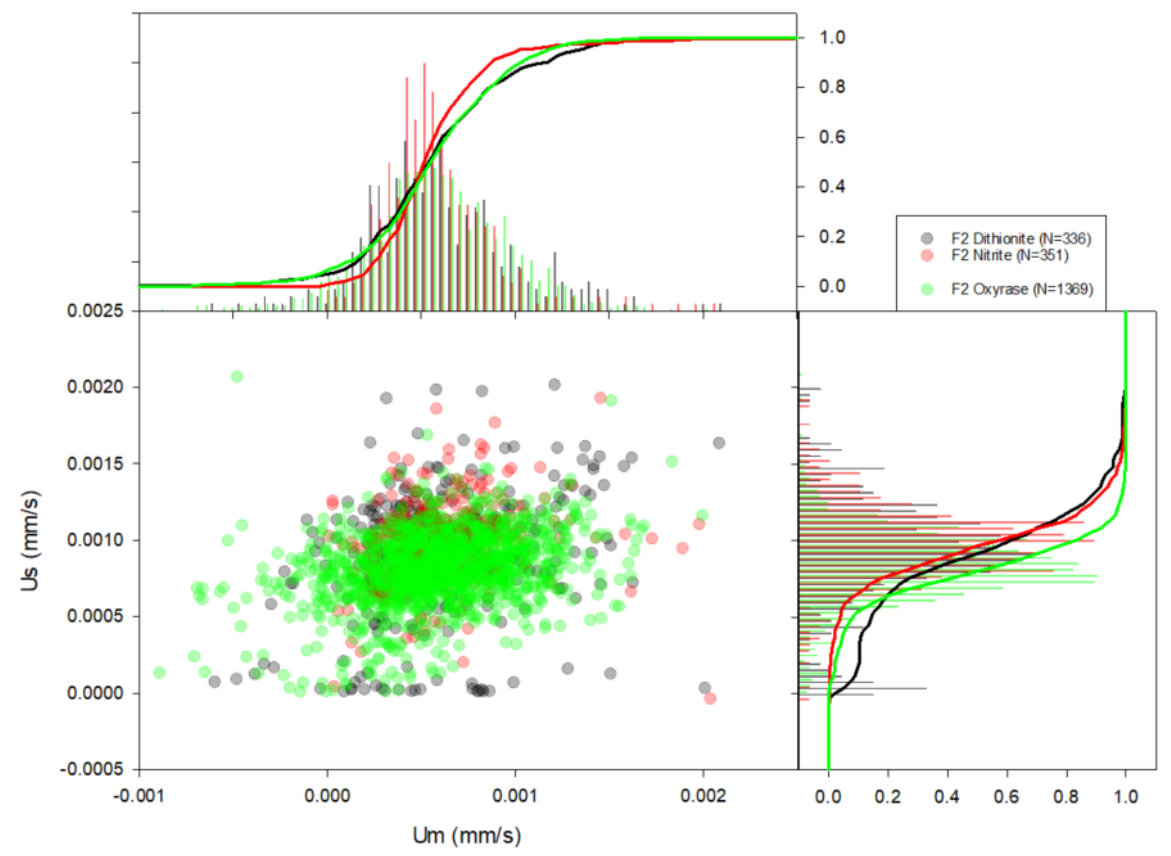

B

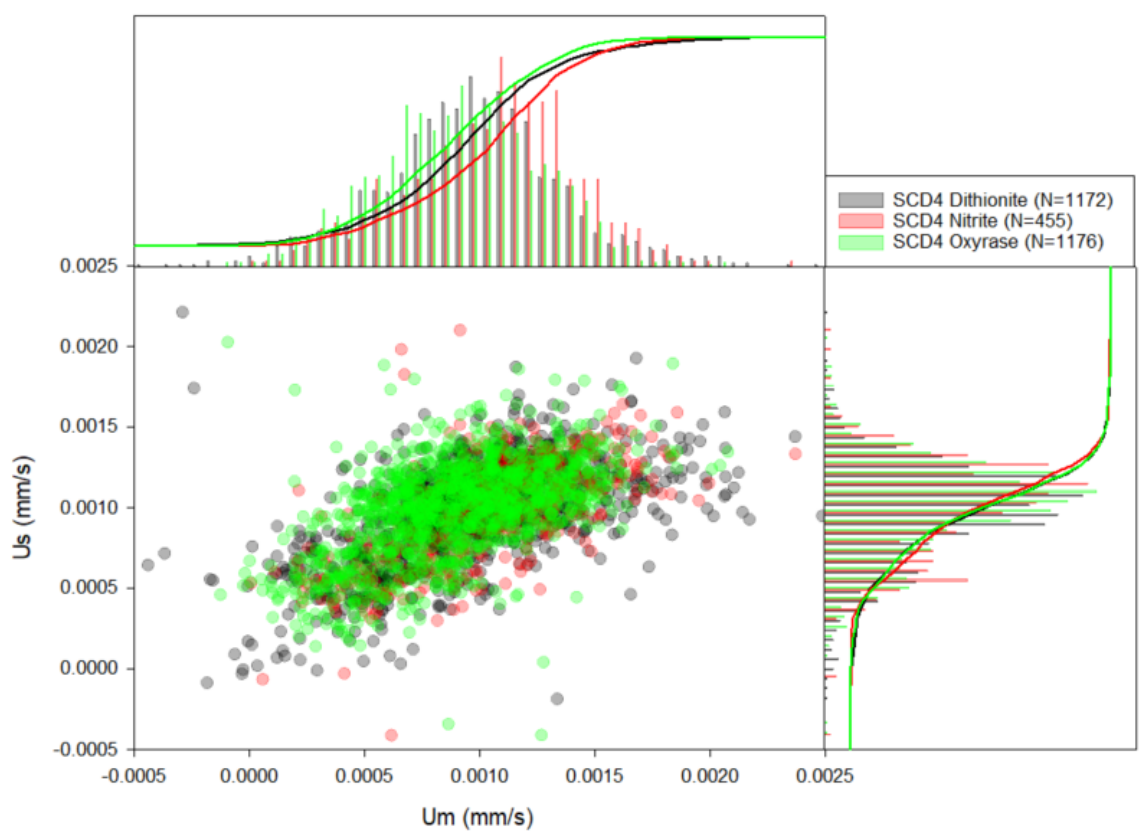



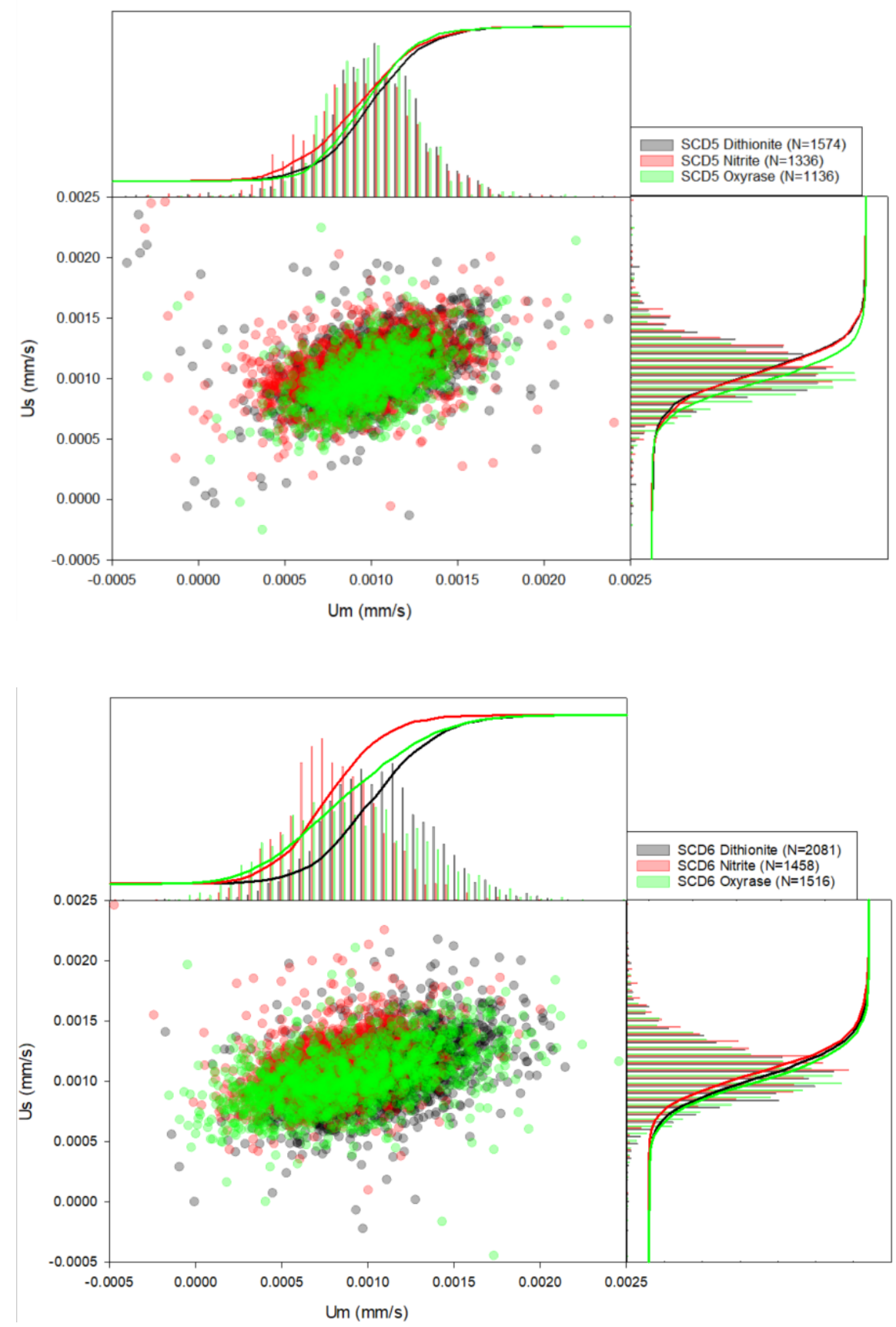

Figure 5. Data from Figure 4, using the experimentally calculated Oxyrase viscosity from $\mathrm{u}_{\mathrm{s}}$ data, are converted to histograms showing the picograms of hemoglobin per cell for healthy (A, left) and SCD (B, right) donors.

A 

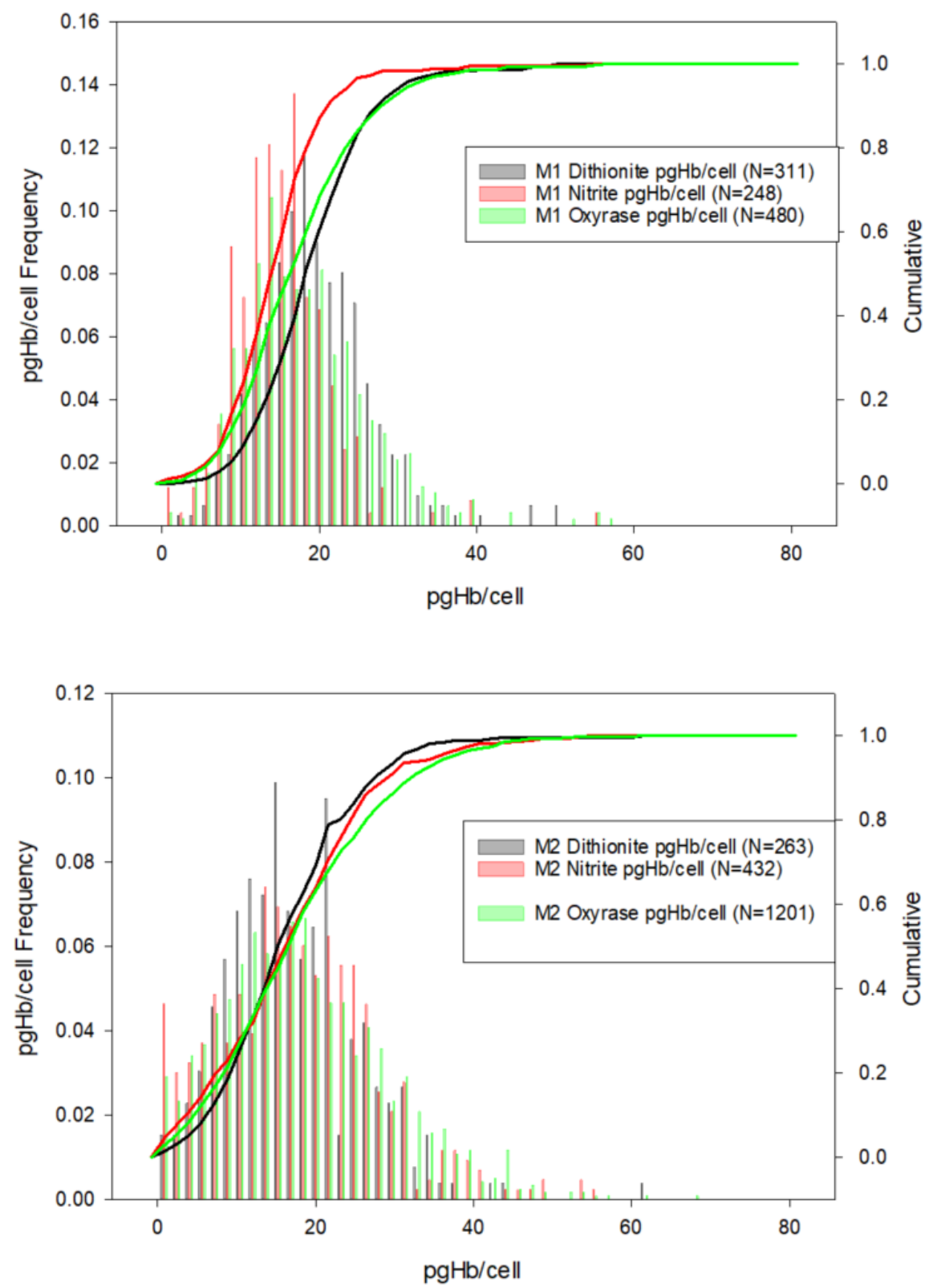

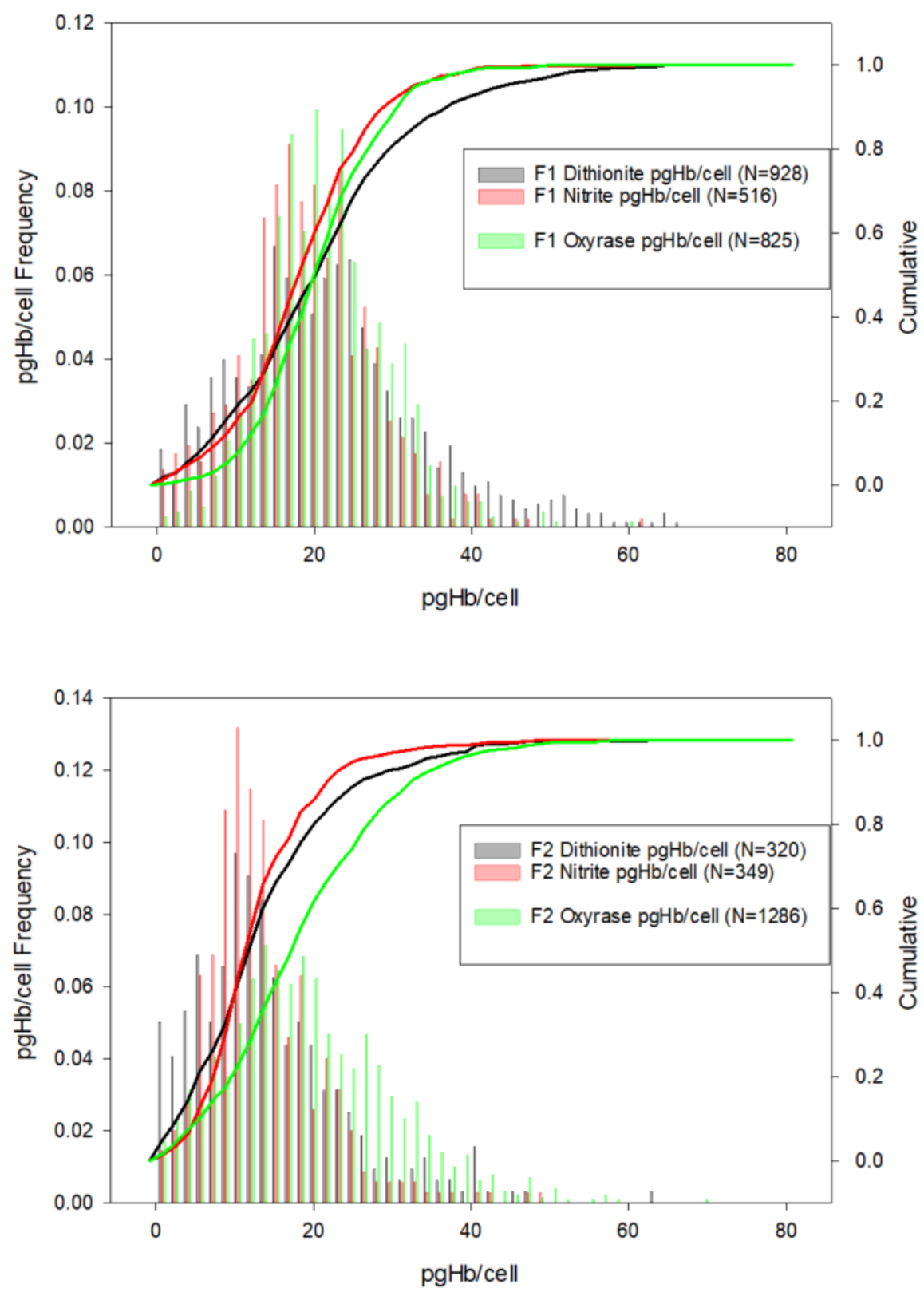

B 

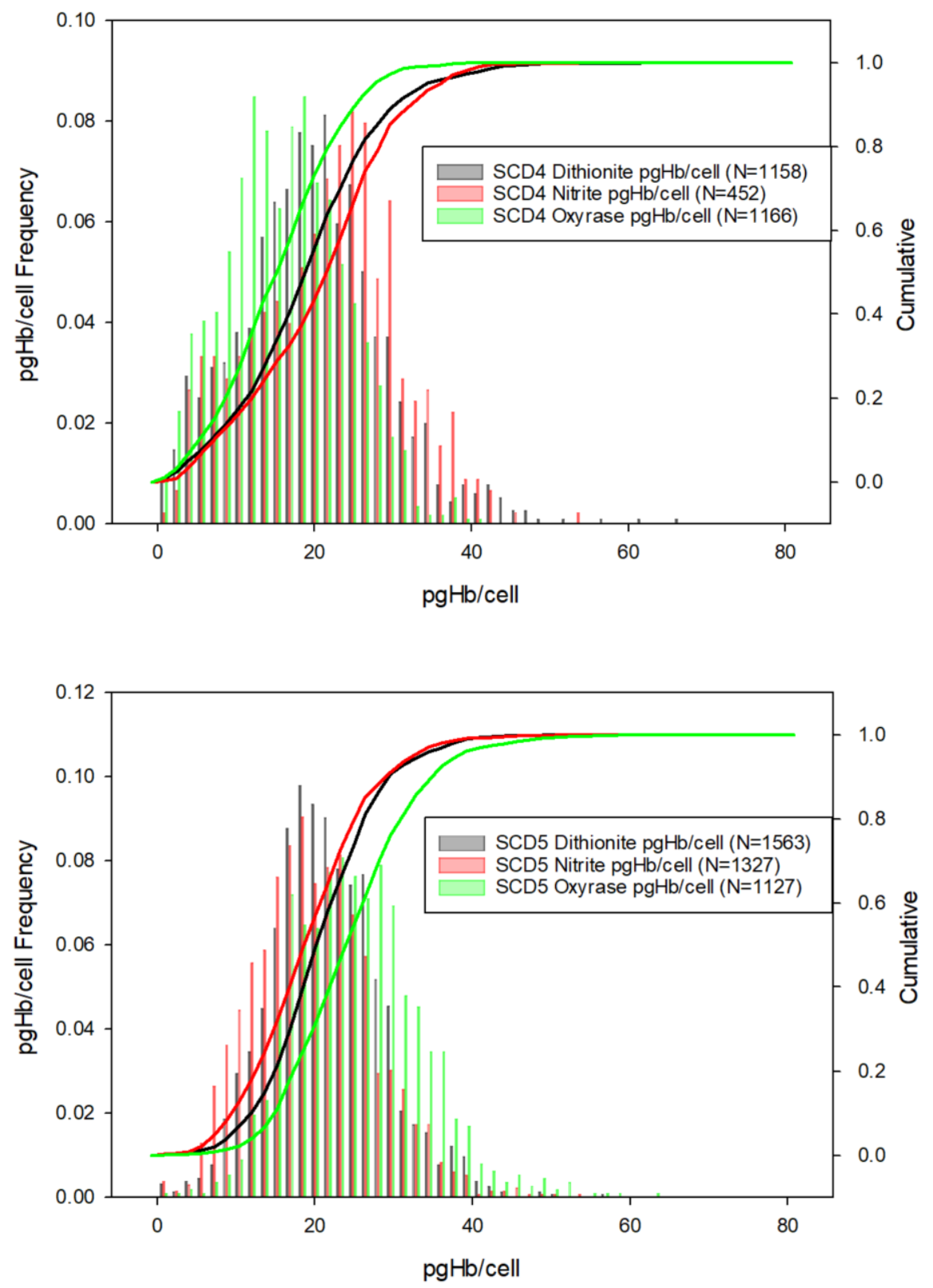


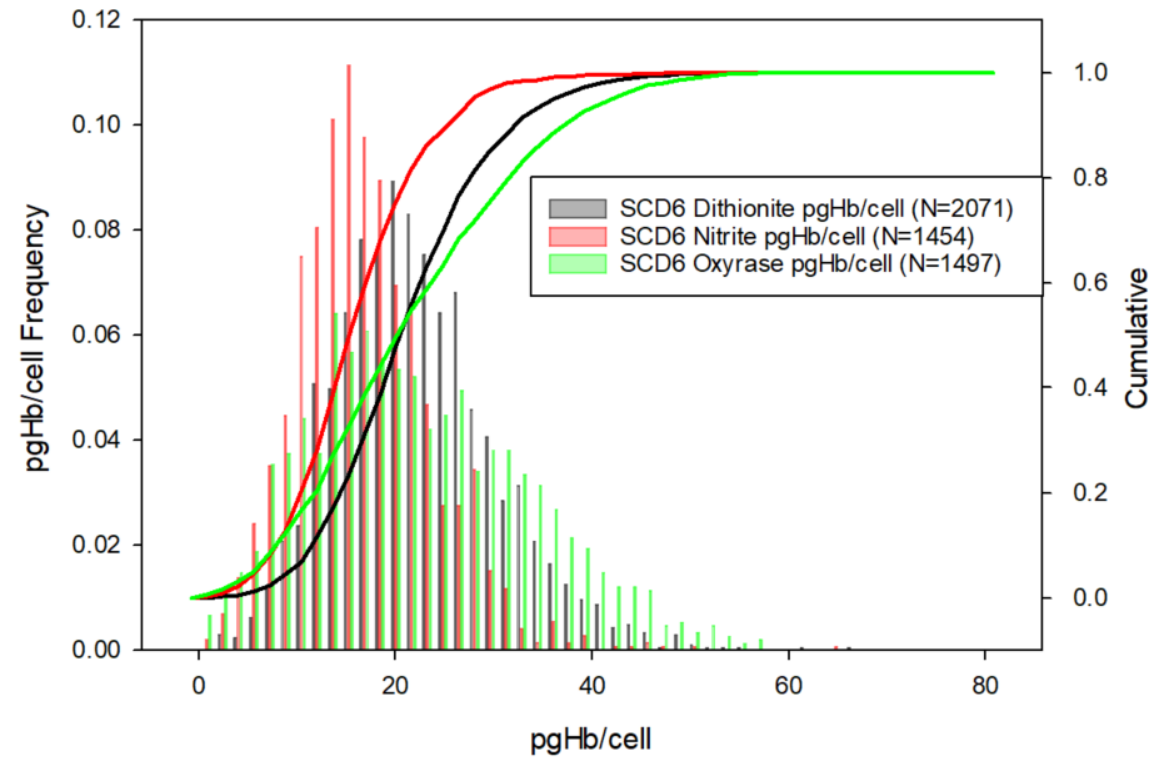

Figure 6. Average pgHb per cell data for all donors inFigure $\mathbf{5}$ are summarized in a bar graph.

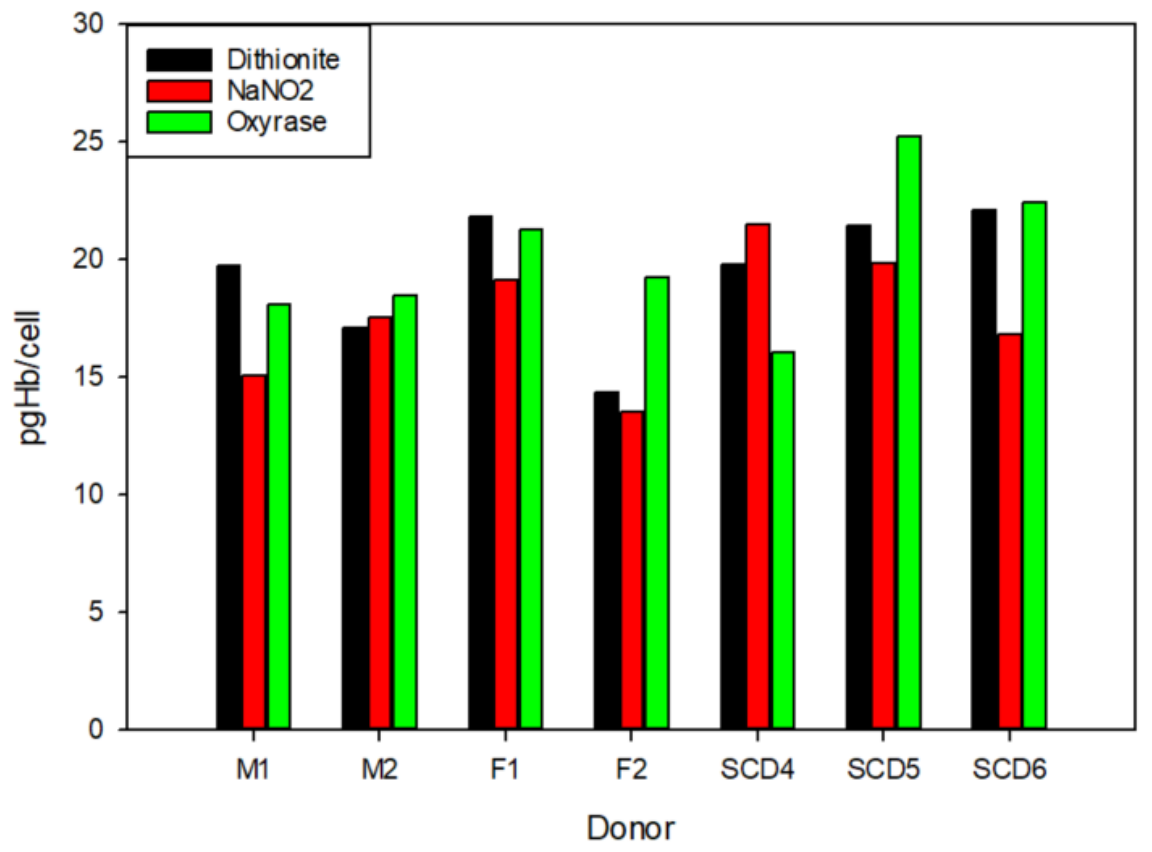

Figure 7. CTV Data from donor F1 (different draw date) using RBC storage buffer (AS-3) with five different $\mathrm{pH}$. Serial additions of $\mathrm{NaOH}$ to increase $\mathrm{pH}$ decrease viscosity and conversion to $\mathrm{pgHb} /$ cell reveals an average of 26.7 (1.1 SD) between the buffers. 


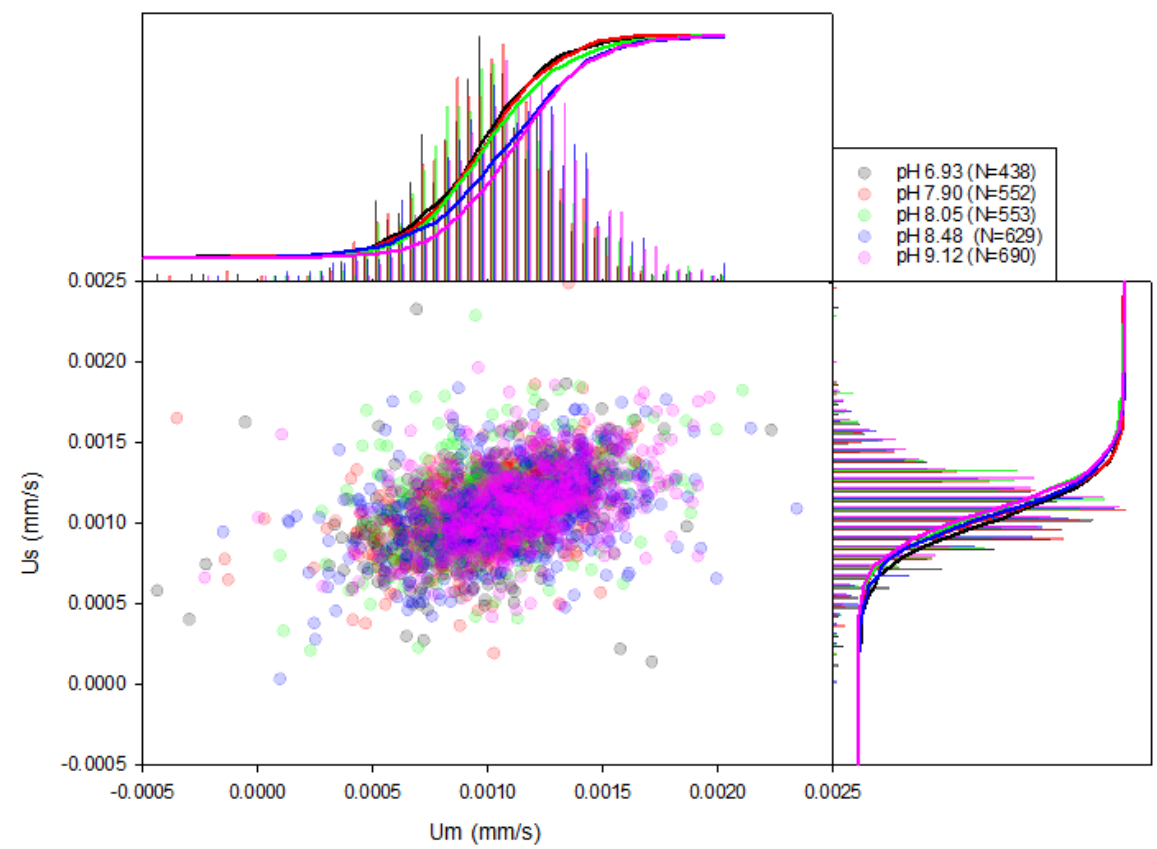

Figure 8. (A) Oxygen dissociation curves for control healthy RBCs and duplicate experimental samples of healthy RBCs undergoing enzymatic deoxygenation and (B) temperature data for the three oxygen dissociation curves.

A

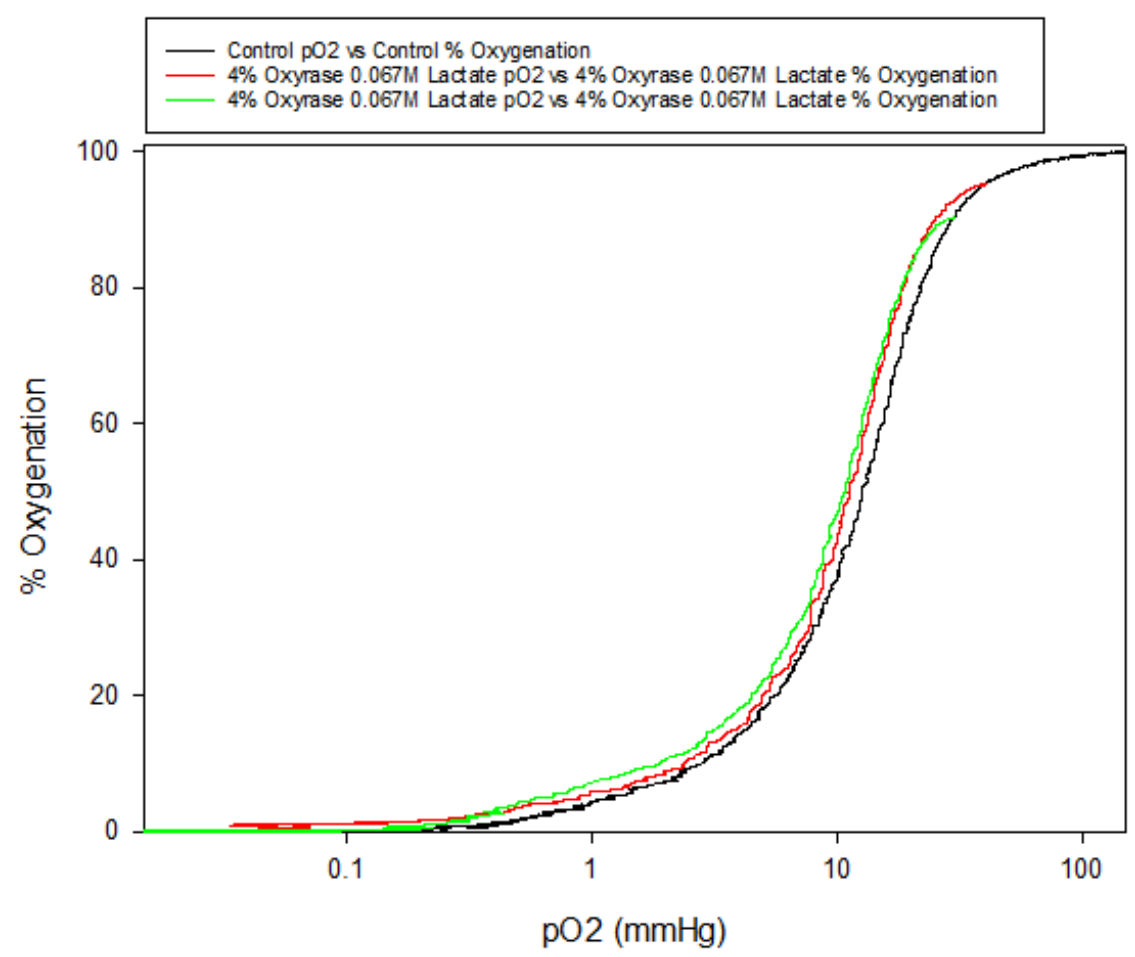


B

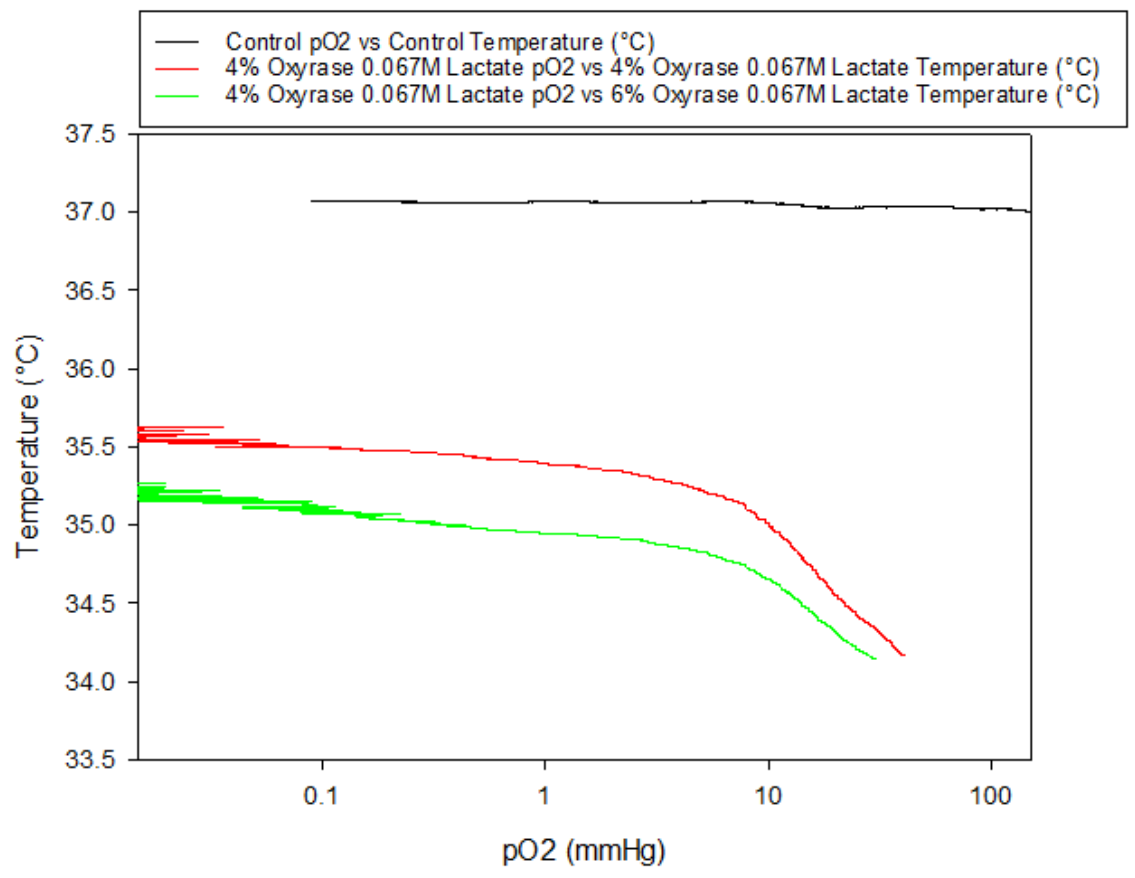

